\title{
Deutschland: \\ Systemische Psychotherapie soll kassenfinanziert werden
}

Peter Schulthess

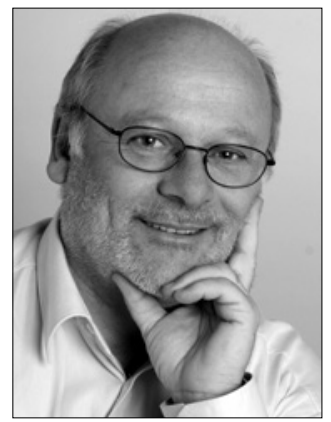

Zehn Jahre nach der Anerkennung der Systemischen Psychotherapie als Verfahren durch den wissenschaftlichen Beirat Psychotherapie hat am 22. November 2018 der gemeinsame Bundesausschuss (G-BA) den Nutzen und die medizinische Notwendigkeit der Systemischen Therapie für Erwachsene bestätigt und damit den Grundstein dafür gelegt, dass Systemische Therapie künftig als Versicherungsleistung aus der gesetzlichen Krankenkasse zu vergüten ist. Der G-BA stellt einen Nutzen in fünf Anwendungsgebieten fest. Bis
März 2019 soll gemäss einer Auskunft des Bundesgesundheitsministeriums das Bewertungsverfahren abgeschlossen sein. Systemische Therapie wird dann als viertes Richtlinienverfahren zur Behandlung psychischer Störungen anerkannt sein.

Peter Schulthess ist Vorstandmitglied der ASP und vertritt diese gemeinsam mit Gabriela Rüttimann in der EAP. Er ist auch Vorsitzender des SARC in der EAP. 